\title{
Studi Analisa Pengaruh Total Harmonic Distortion (THD) terhadap Rugi-Rugi, Efisiensi, dan Kapasitas Kerja Transformator pada Penyulang Kerobokan
}

\author{
I Putu Adi Wirajaya, I Wayan Rinas*, I Wayan Sukerayasa \\ Program Studi Teknik elektro, Fakultas Teknik, Universitas Udayana \\ *Email : rinas@unud.ac.id
}

\begin{abstract}
Abstrak
Penyulang Kerobokan menyuplai energi listrik didaerah Kerobokan. Penyulang ini menyuplai 67 transfomator distribusi yang melayani berbagai macam pelanggan dengan beban listrik nonlinier. Beban listrik nonlinier menimbulkan harmonisa yang berpengaruh buruk terhadap pelanggan dan peralatan sistem tenaga listrik terutama transformator distribusi. Pada Penyulang Kerobokan hanya $3(4,5 \%)$ dari total 67 transformator yang memiliki kandungan THDi (Total Harmonic Distortion Arus) memenuhi standar IEEE 519-2014 dan 64 (95,5\%) dari total 67 transformator memiliki kandungan THDi yang tinggi dan melebihi standar IEEE 5192014. Untuk itu dilakukan analisis rugi-rugi daya, efisiensi, dan kapasitas kerja transformator akibat pengaruh THDi. Penelitian ini menggunakan metode pengukuran langsung pada seluruh transformator di Penyulang Kerobokan dan simulasi pada program ETAP Powerstation. Hasil analisis menunjukan rugi-rugi daya total tanpa pengaruh THDi pada seluruh transformator sebesar 49,4 kW dan setelah terpengaruh THDi menjadi sebesar 591,71 kW. Kandungan THDi terbesar terdapat pada transformator KA 0992 yaitu 24,8\% yang mengakibatkan peningkatan rugi-rugi daya sebesar $12,02 \mathrm{~kW}$ atau $12,02 \%$ dari kapasitasnya dan mengalami penurunan efisiensi yaitu 12,66\% serta penurunan kapasitas kerja sebesar 19,9\%. Sedangkan kandungan THDi terkecil terdapat pada transformator DB 449 yaitu 6,8\% yang mengakibatkan peningkatan rugi-rugi daya sebesar $2,2 \mathrm{~kW}$ atau $0,88 \%$ dari kapasitasnya dan mengalami penurunan efisiensi yaitu 1,01\% serta penurunan kapasitas kerja sebesar 2,7\%.
\end{abstract}

Kata Kunci : THDi, Rugi-rugi Daya, Efisiensi, Penurunan Kapasitas Kerja

\begin{abstract}
Kerobokan feeder supply electrical energy in the area of Kerobokan. This feeder supplies 67 distribution transformers that serve a variety of customers with nonlinier electrical loads. Nonlinier electrical loads cause harmonics which adversely affect customers and power system equipment, especially distribution transformers. In Kerobokan feeder, only 3 (4.5\%) of the 67 transformers has THDi content that according with the IEEE 519-2014 standard and 64 (95.5\%) of the 67 transformers has a high THDi content and exceed the IEEE 519-2014 standard. For this reason, the power losses, efficiency, and work capacity of the transformer are analyzed due to the effect of THDi. This study uses a direct measurement method in all transformers in the Kerobokan feeder and simulation on the ETAP Powerstation program. The results of the analysis showed that total power losses without being affected by THDi for all transformers were $49.4 \mathrm{~kW}$ and after being affected by THDi were $591.71 \mathrm{~kW}$. The highest THDi content is in the KA 0992 transformer is $24.8 \%$ which results in an increased in power losses is $12.02 \mathrm{~kW}$ or $12.02 \%$ of its capacity and a decreased in efficiency is $12.66 \%$ and has a decreased in work capacity is $19.9 \%$. While the smallest THDi content is found in the DB 449 transformer is $6.8 \%$ which results in an increased in power losses is $2.2 \mathrm{~kW}$ or $0.88 \%$ of its capacity and a decreased efficiency is $1.01 \%$ and has a decreased in work capacity is $2.7 \%$.
\end{abstract}

Keywords : THDi, Power Losses, Efficiency, Decreased work capacity

\section{PENDAHULUAN}

Energi listrik merupakan kebutuhan primer yang tidak dapat dipisahkan dari

kehidupan meningkatnya masyarakat, mebutuhakat,_seiring 
maka penyedia energi listrik juga harus memperhatikan peralatan-peralatan penyaluran energi listrik agar tetap memiliki keandalan dan kontinuitas penyaluran energi listrik yang baik. Salah satu peralatan energi listrik yang paling penting adalah transformator distribusi. Transformator distribusi merupakan peralatan sistem tenaga listrik yang berfungsi untuk menurunkan tegangan dari tegangan menengah $20 \mathrm{kV}$ ke tegangan rendah 380/220 V. Transformator distribusi merupakan peralatan energi listrik yang mahal dan sangat penting dalam penyaluran energi listrik, sehingga diharapkan dapat beroperasi terus menerus secara optimal untuk menyalurkan energi listrik kepada konsumen.

Penyulang Kerobokan merupakan penyulang yang disuplai oleh transformator I dengan kapasitas transformator 60 MVA di Gardu Induk Padang Sambian. Penyulang Kerobokan mensuplai 67 buah transformator distribusi dengan total beban yang dilayani yaitu 5.317,267 kVA. Beban yang disuplai terdiri dari berbagai macam beban-beban listrik seperti beban rumah tangga, industri, dan pabrik yang menggunakan peralatan elektronik yang didalamnya terdapat komponen semi konduktor seperti inverter, komputer, baterai charger, dan lain sebagainya yang menyebabkan timbulnya arus harmonisa. Dalam standar IEEE 519-2014 berisikan rekomendasi batasan-batasan kandungan harmonisa dalam sistem tenaga listrik, baik itu harmonisa tegangan ataupun harmonisa arus [1]. Arus harmonisa mengakibatkan terjadinya distorsi tegangan dan arus sehingga gelombang tegangan dan arus yang dihasilkan tidak sinusoidal murni yang akhirnya menimbulkan pemanasan yang berlebih dan mengakibatkan gangguan hingga kerusakan pada peralatan sistem tenaga listrik, terutama transformator distribusi. Transformator distribusi di Penyulang Kerobokan 64 (95,5\%) dari total 67 transformator memiliki kandungan THDi yang tinggi dan melebihi standar IEEE 5192014.

Berdasarkan permasalahan tersebut, maka dilakukan penelitian Studi Analisa Pengaruh Total Harmonic Distortion (THD) Terhadap Rugi-Rugi, Efisiensi, dan Kapasitas Kerja Transformator pada Penyulang Kerobokan.

\section{KAJIAN PUSTAKA}

Sistem distribusi tenaga listrik merupakan suatu sistem yang menyalurkan energi listrik dari gardu induk (GI) hingga ke konsumen. Jaringan distribusi dibagi menjadi dua, yaitu jaringan distribusi primer dan jaringan distribusi sekunder. Jaringan distribusi primer merupakan jaringan yang berada diantara gardu induk dengan gardu distribusi dan memiliki tegangan sistem 20 kV. Sedangkan jaringan distribusi sekunder merupakan jaringan yang berfungsi mendistribusikan tenaga listrik dari gardugardu pembagi (gardu distribusi) ke pusat beban (konsumen tenaga listrik).

\section{A. Gardu Distribusi}

Gardu distribusi tenaga listrik adalah bangunan gardu listrik yang terdiri dari instalasi Perlengkapan Hubung Bagi Tegangan Menengah (PHB-TM), Transformator Distribusi (TD), dan Perlengkapan Hubung Bagi Tegangan Rendah (PHB-TR) untuk memenuhi kebutuhan tenaga listrik bagi konsumen baik dengan Tegangan Menengah (TM 20 $\mathrm{kV}$ ) maupun konsumen dengan Tegangan Rendah (TR 220/380 V) [2].

B. Karakteristik Beban

Karakteristik beban pada sistem ketenagalistrikan dibedakan menjadi dua, yaitu beban linier dan beban non linier.

a. Beban Linier

Beban linier adalah beban yang komponen arusnya proporsional terhadap tegangannya. Contoh beban linier yaitu motor listrik, lampu pijar, pemanas, dan lain sebagainya [3].

b. Beban Non Linier

Beban non linier merupakan beban yang komponen arusnya tidak proporsional dengan komponen tegangannya, sehingga bentuk gelombang arus dan bentuk gelombang tegangannya tidak sama. Contoh beban non linier antara lain penyearah, komputer, pengaturan kecepatan motor, motor DC, UPS dan lain-lainnya [3].

C. Total Harmonic Distortion (THD) Total Harmonic Distortion (THD) adalah ukuran nilai efektif dari komponen harmonisa dari bentuk gelombang yang terdistorsi. Indeks ini bisa dihitung untuk tegangan dan arus [4]. Total Harmonic Distortion (THD) digunakan untuk 
menyatakan besarnya distorsi harmonisa pada sistem tenaga listrik.

D. Standar IEEE 519-2014

Standar IEEE 519-2014 merupakan revisi dari standar IEEE 519-1992. Standar IEEE 519-2014 merupakan standar yang berisikan tentang batasan-batasan kandungan harmonisa yang terdapat dalam sistem tenaga listrik, baik itu harmonisa tegangan ataupun harmonisa arus. Batasbatas yang direkomendasikan akan diaplikasikan sesuai dengan point of common coupling (PCC) antara owner maupun users [1].

a. Standar THD Tegangan (THDv)
Berdasarkan standar IEEE 519-2014, pada tabel 1 dapat dilihat standar untuk THD tegangan (THDv) [1].

Tabel 1 Voltage Distortion Limits [1]

\begin{tabular}{|c|c|c|}
\hline $\begin{array}{c}\text { Bus Voltage (V) at } \\
\text { PCC }\end{array}$ & $\begin{array}{c}\text { Individual } \\
\text { Harmonic } \\
\text { (\%) }\end{array}$ & $\begin{array}{c}\text { Total } \\
\text { Harmonic } \\
\text { Distortion } \\
(\%)\end{array}$ \\
\hline $\mathrm{V} \leq 1 \mathrm{kV}$ & 5,0 & 8,0 \\
\hline $1 \mathrm{kV}<\mathrm{V}<69 \mathrm{kV}$ & 3,0 & 5,0 \\
\hline $69 \mathrm{kV}<\mathrm{V}<161 \mathrm{kV}$ & 1,5 & 2,5 \\
\hline $161 \mathrm{kV}<\mathrm{V}$ & 1,0 & $1,5^{\mathrm{a}}$ \\
\hline
\end{tabular}

b. Standar THD arus (THDi)

Berdasarkan standar IEEE519-2014 untuk THDi nilai batas yang digunakan sebagai standar disesuaikan dengan short circuit ratio (rasio hubung singkat) dan dapat dilihat pada tabel 2 [1].

Tabel 2 Current Distortion Limits for Systems Rated $120 \mathrm{~V}$ through $69 \mathrm{kV}$ [1]

\begin{tabular}{|c|c|c|c|c|c|c|}
\hline \multicolumn{7}{|c|}{ Individuan Harmonic Order (odd harmonic $)^{a, D}$} \\
\hline$I_{S C} / I_{\mathrm{L}}$ & $3 \leq \mathrm{h} \leq 11$ & $11 \leq \mathrm{h} \leq 17$ & $17 \leq \mathrm{h} \leq 23$ & $23 \leq \mathrm{h} \leq 35$ & $35 \leq \mathrm{h} \leq 50$ & THD (\%) \\
\hline$<20^{C}$ & 4,0 & 2,0 & 1,5 & 0,6 & 0,3 & 5,0 \\
\hline $20<50$ & 7,0 & 3,5 & 2,5 & 1,0 & 0,5 & 8,0 \\
\hline $50<100$ & 10,0 & 4,5 & 4,0 & 1,5 & 0,7 & 12,0 \\
\hline $100<1000$ & 12,0 & 5,5 & 5,0 & 2,0 & 1,0 & 15,0 \\
\hline$>1000$ & 15,0 & 7,0 & 6,0 & 2,5 & 1,4 & 20,0 \\
\hline
\end{tabular}

E. Short Circuit Ratio $\left(\mathrm{SC}_{\text {ratio }}\right)$

Short Circuit Ratio $\left(\mathrm{SC}_{\text {ratio }}\right)$ merupakan hasil bagi antara arus hubung singkat $\left(\mathrm{I}_{\mathrm{SC}}\right)$ dan arus beban $\left(\mathrm{I}_{\mathrm{L}}\right)$. Adapun persamaan dari $\mathrm{SC}_{\text {ratio }}$ adalah.

$$
\mathrm{SC}_{\text {ratio }}=\frac{\mathrm{ISC}_{\mathrm{SC}}}{\mathrm{I}_{\mathrm{L}}}
$$

Keterangan :

$\mathrm{SC}_{\text {ratio }}$ : Rasio Hubung Singkat (Short Circuit Ratio)

IsC $\quad$ : Arus Hubung Singkat

$\mathrm{I}_{\mathrm{L}} \quad$ : Arus Beban Penuh

Untuk arus hubung singkat $\left(\mathrm{I}_{\mathrm{SC}}\right)$ dapat dicari dengan persamaan berikut.

$$
\mathrm{I}_{\mathrm{SC}}=\frac{\mathrm{kVA \times 100}}{\sqrt{3} \times \mathrm{kV} \times \mathrm{Z}(\%)} \ldots
$$

Keterangan :
kVA : Kapasitas Transformator
kV : Tegangan Sekunder
Transformator
Z : Impedansi Transformator

Sedangkan untuk arus beban penuh $\left(\mathrm{I}_{\mathrm{L}}\right)$ dapat dicari dengan persamaan berikut.

$$
\mathrm{I}_{\mathrm{L}}=\frac{\mathrm{kW}}{\mathrm{PF} \times \sqrt{3} \times \mathrm{kV}} \text {. }
$$

Keterangan :

PF : Faktor Daya

kW : Total Daya Aktif

F. Rugi-rugi Daya pada Transformator Akibat Harmonisa

Adanya kandungan harmonisa akan meningkatkan rugi-rugi daya pada transformator. Rugi-rugi daya pada suatu transformator dapat disebut dengan load loss $\left(\mathrm{P}_{\mathrm{LL}}\right)$. Dalam satuan per unit (p.u), load loss $\left(\mathrm{P}_{\mathrm{LL}}\right)$ dapat dihitung dengan persamaan berikut [4].

$$
\mathrm{P}_{\mathrm{LL}}=\sum \mathrm{I}_{\mathrm{h}}^{2}+\left(\sum \mathrm{I}_{\mathrm{h}}^{2} \mathrm{xh}^{2}\right) \times \mathrm{P}_{\mathrm{EC}-\mathrm{R}} \text { (p. u) } \ldots
$$

Keterangan :

$\mathrm{P}_{\mathrm{EC}-\mathrm{R}} \quad$ : Eddy Current Loss Factor

$\mathrm{h}$ : Orde harmonisa

$\mathrm{I}_{\mathrm{h}} \quad$ : Arus harmonisa

$\sum \mathrm{I}_{\mathrm{h}}^{2} \quad$ : Komponen dari rugi tembaga $\left(\mathrm{I}^{2} \mathrm{R}\right)$ yang dinyatakan dalam satuan per unit (p.u)

$\left(\sum \mathrm{I}_{\mathrm{h}}^{2} \mathrm{xh}^{2}\right) \times \mathrm{P}_{\mathrm{EC}-\mathrm{R}}$ : Faktor rugi arus eddy yang dinyatakan dalam satuan per unit (p.u) 
Untuk faktor eddy current loss $\left(\mathrm{P}_{\mathrm{EC}-\mathrm{R}}\right)$ dapat dilihat pada tabel 3 dibawah [4].

Tabel 3 Typical Values of PEC-R [4]

\begin{tabular}{|c|c|c|c|}
\hline \multirow{2}{*}{ Type } & MVA & Voltage & $\begin{array}{c}\mathrm{P}_{\mathrm{EC}-\mathrm{R}} \\
(\%)\end{array}$ \\
\hline \multirow{3}{*}{ Dry } & $\leq 1$ & - & $3-8$ \\
\cline { 2 - 4 } & $\leq 1,5$ & $5 \mathrm{kV}$ (High Voltage) & $12-20$ \\
\cline { 2 - 4 } & $\leq 1,5$ & $15 \mathrm{kV}$ (High Voltage) & $9-15$ \\
\hline \multirow{2}{*}{$\begin{array}{c}\text { Oil- } \\
\text { filled }\end{array}$} & $\leq 2,5$ & 480V (Low Voltage) & 1 \\
\cline { 2 - 4 } & $2,5-5$ & 480V (Low Voltage) & $1-5$ \\
\cline { 2 - 4 } & $>5$ & 480V (Low Voltage) & $9-15$ \\
\hline
\end{tabular}

Untuk rugi histerisis $\left(\mathrm{P}_{\mathrm{h}}\right)$ akibat pengaruh harmonisa dapat dihitung dengan menggunakan persamaan berikut [5].

$$
P_{h}=K_{h} \times \sum_{h=1}^{\infty} i_{h} \times h .
$$

Keterangan :

$\mathrm{K}_{\mathrm{h}} \quad$ : Konstanta histerisis diketahui sebesar 0,26

$\mathrm{i}_{\mathrm{h}} \quad$ : Arus harmonisa

h : Orde harmonisa

\section{G. Efisiensi Transformator}

Suatu transformator diharapkan memiliki efisiensi yang tinggi agar dapat melayani beban secara maksimal. Tingkat efisiensi suatu transformator dapat dihitung dengan perssamaan berikut [6].

$\%$ Efficiency $=\left[1-\frac{\sum \text { Rugi Total }}{\text { Daya Input }}\right] \times 100 \% \ldots$

Daya Input $=\mathrm{S} \times \cos \varphi$

H. Derating Transformator

Derating transformator atau penurunan kapasitas kerja transformator terjadi akibat adanya pengaruh harmonisa arus yang dapat menimbulkan pemanasan pada komponen transformator, sehingga akan mengakibatkan peningkatan rugi-rugi dan penurunan efisiensi pada transformator.

Untuk melakukan perhitungan penurunan kapasitas daya terpasang transformator, digunakan metode perhitungan nilai THDF (Transformator Harmonic Derating Factor). THDF merupakan faktor pengali yang digunakan untuk menghitung besar kapasitas baru (kVA baru) transformator. Nilai THDF dapat ditentukan dengan menggunakan persamaan [7].
$\mathrm{THDF}=\frac{1,414 \times(\text { arus phase } \mathrm{rms})}{\text { (arus puncak phase sesaat })} \times 100 \% \ldots$ (8)

kVA baru $=$ THDF $x$ kVA pengenal...$(9)$

Keterangan :

THDF = Transformator Harmonic Derating Factor

\section{METODE PENELITIAN}

Penelitian dilakukan di PT. PLN (Persero) Rayon Mengwi yang beralamat di Jl. Raya Abianbase, Kapal, Mengwi, Kabupaten Badung, Bali. Pada penelitian ini dilakukan pengukuran THDi dan THDV pada seluruh transformator di Penyulang Kerobokan dan membandingkannya dengan standar IEEE 519-2014. Pemodelan single line diagram Penyulang Kerobokan menggunakan program ETAP Power Station untuk mengetahui rugi-rugi daya transformator tanpa terpengaruh THDi, selanjutnya dihitung efisiensi seluruh transformator tanpa terpengaruh THDi. Dari hasil pengukuran THDi seluruh transformator di Penyulang Kerobokan dilakukan perhitungan rugi-rugi daya dan efisiensi transformator setelah terpengaruh THDi, kemudian membandingkannya dengan rugi-rugi daya dan efisiensi transformator tanpa terpengaruh THDi. Terakhir dilakukan perhitungan penurunan kapasitas kerja pada seluruh transformator di Penyulang Kerobokan.

\section{HASIL DAN PEMBAHASAN}

A. Batas Maksimum THDi dan THDV Masing-Masing Transformator di Penyulang Kerobokan

Batas maksimum THDi pada sistem kelistrikan menurut standar IEEE 519-2014 didapatkan dengan mengetahui $\mathrm{SC}_{\text {ratio }}$. $\mathrm{SC}_{\text {ratio }}$ dapat dihitung dengan persamaan 1. Didapatkan hasil nilai $\mathrm{SC}_{\text {ratio }}$ yang berbedabeda dikarenakan beban yang dipikul masing-masing transformator juga berbeda. Perbandingan hasil pengukuran THDi dengan standar IEEE 519-2014 pada masing-masing transformator di Penyulang Kerobokan hanya terdapat $3(4,5 \%)$ dari total 67 transformator memiliki kandungan THDi yang memenuhi standar IEEE 5192014 dan $64(95,5 \%)$ dari total 67 transformator memiliki kandungan THDi yang tinggi dan melebihi standar IEEE 519- 
2014. Kandungan THDi tertinggi terdapat pada transformator KA 0992 yaitu sebesar 24,8\%, sedangkan transformator yang memiliki kandungan THDi yang terkecil adalah transformator DB 449 yaitu sebesar $6,8 \%$ dan dapat dilihat pada tabel 4 .

Tabel 4 Perbandingan Hasil Pengukuran THDi dengan Standar IEEE 519-2014

\begin{tabular}{|c|c|c|c|c|c|}
\hline \multirow{2}{*}{ No } & Transformator & $\mathbf{k V A}$ & $\begin{array}{c}\text { Thsil } \\
\text { Pengukuran } \\
\text { Transformator }\end{array}$ & $\begin{array}{c}\text { Standar } \\
\text { IEEE 519- } \\
\mathbf{2 0 1 4}\end{array}$ & \multirow{2}{*}{ Keterangan } \\
\hline 1 & DB 449 & 250 & $6,8 \%$ & $12 \%$ & Sesuai Standar \\
\hline $\mathbf{2}$ & KA 0992 & $\mathbf{1 0 0}$ & $\mathbf{2 4 , 8 \%}$ & $\mathbf{1 2 \%}$ & Melebihi Standar \\
\hline 3 & KA 1581 & 100 & $15 \%$ & $15 \%$ & Sesuai Standar \\
\hline 4 & KA 3701 & 50 & $14,3 \%$ & $15 \%$ & Sesuai Standar \\
\hline
\end{tabular}

THDV menurut standar IEEE 519-2014 untuk tegangan diantara $1 \mathrm{kV}$ hingga $69 \mathrm{kV}$ (1 $\mathrm{kV}<\mathrm{V}<69 \mathrm{kV}$ ) adalah 5\% dan seluruh transformator di Penyulang Kerobokan memiliki nilah THDv yang sesuai standar.

B. Pemodelan Single Line Diagram Penyulang Kerobokan pada Program ETAP Power Station program ETAP Power Station digunakan untuk mengetahui karakteristik gelombang serta spektrum THDi pada transformator dan mengetahui rugi-rugi daya transformator sebelum terpengaruh THDi. Pemodelan pada program ETAP Power Station dapat dilihat pada gambar 1.

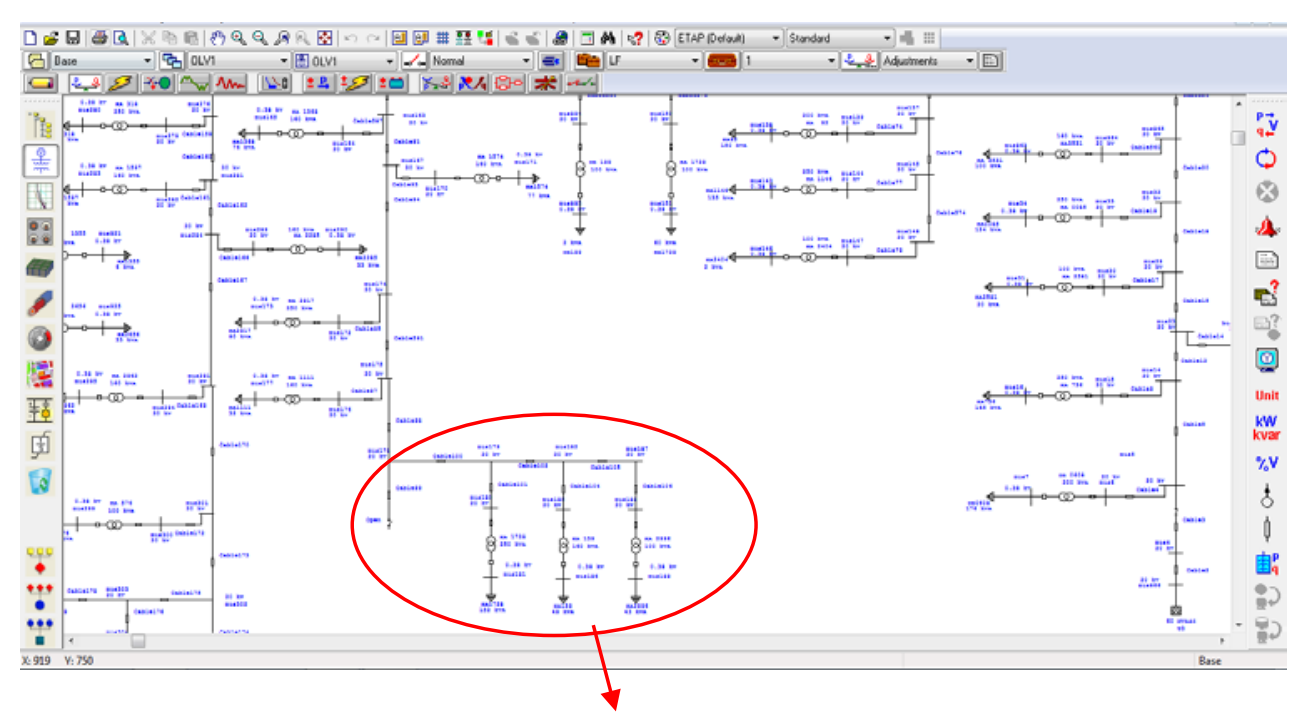




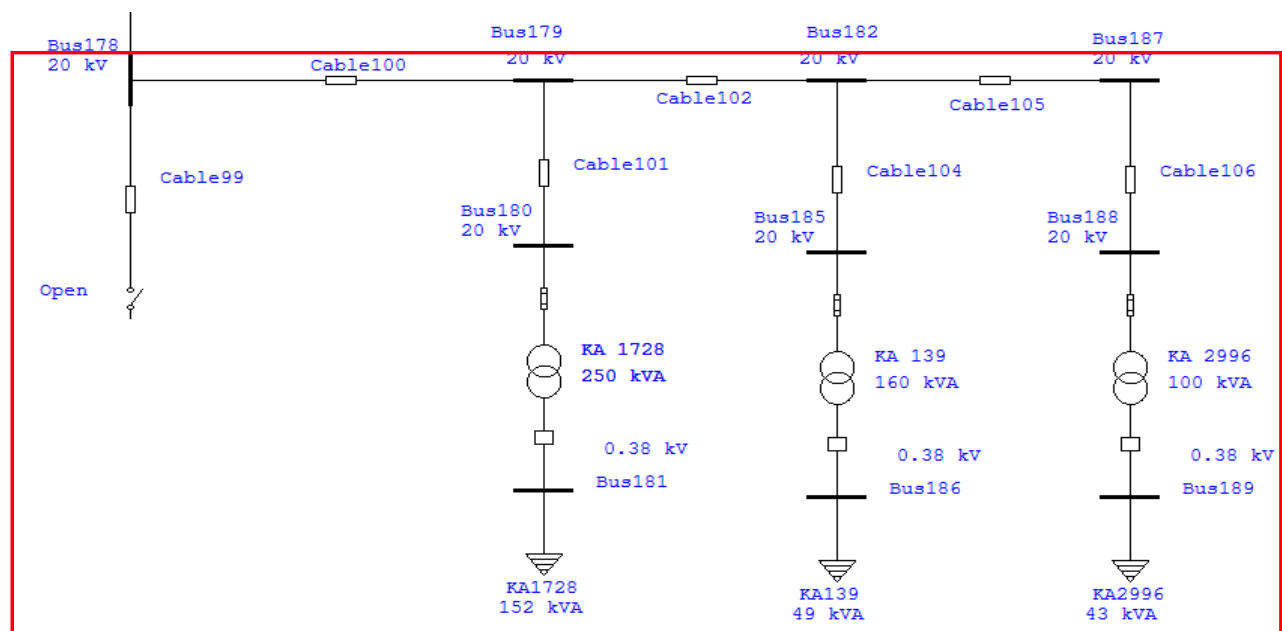

Gambar 1 Pemodelan Jaringan Distribusi 20 KV Penyulang Kerobokan pada Program ETAP Power Station

C. Gelombang dan Spektrum THDi pada Transformator di Penyulang Kerobokan

Pada gambar 2 dapat dilihat bahwa karakteristik dari gelombang dan spektrum THDi pada transformator KA 1146 untuk orde ganjil mulai dari orde ke-3 hingga orde ke-19 mengalami fluktuasi kandungan harmonisa yang dikarenakan beban yang disuplai identik dengan beban listrik rumah tangga. Sedangkan pada gambar 3 dapat dilihat karakteristik gelombang dan spektrum THDi pada transformator KA 3391 untuk orde ganjil mulai dari orde ke-3 hingga orde ke-19 mengalami penurunan kandungan harmonisa yang dikarenakan transformator KA 3391 merupakan transformator khusus yang hanya melayani beban

industri.
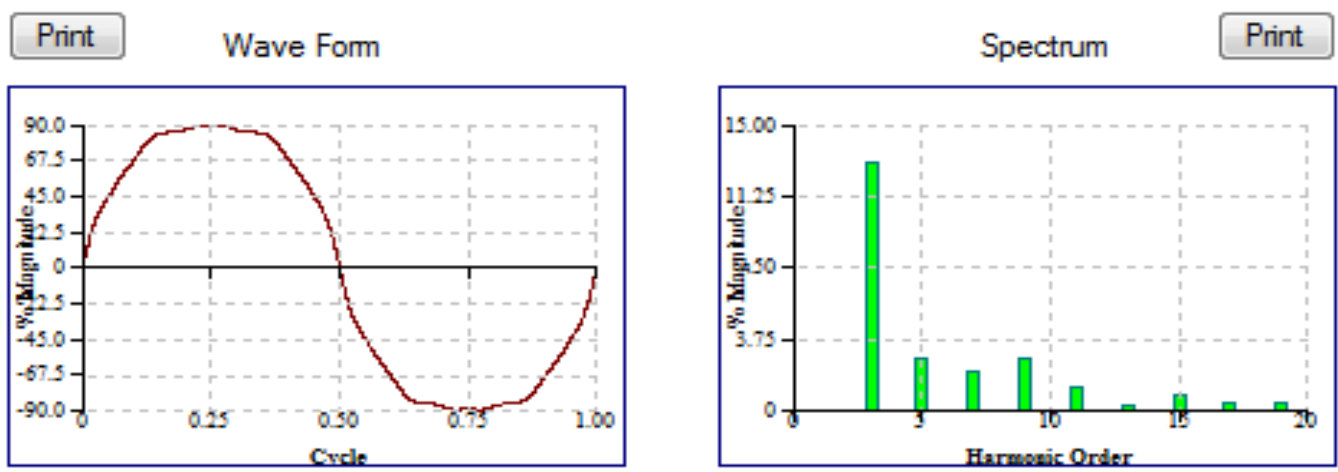

Gambar 2 Karakteristik Gelombang dan Spektrum THDi Beban Listrik Rumah Tangga pada Transformator KA 1146
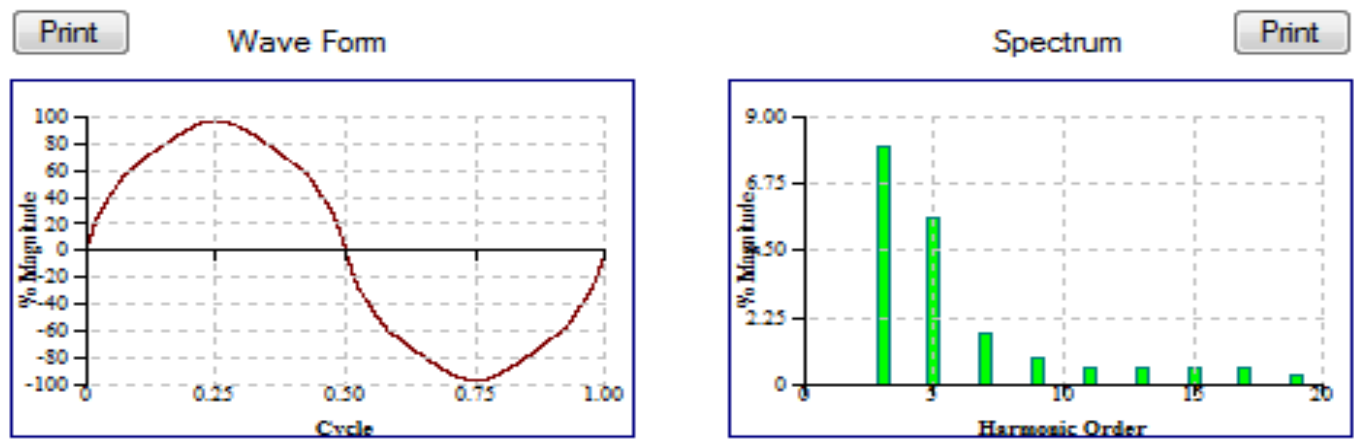

Gambar 3 Karakteristik Gelombang dan Spektrum THDi Beban Listrik Industri pada Transformator KA 3391 
D. Rugi-Rugi Daya Transformator Tanpa Pengaruh THDi

Pada program ETAP Power Station dilakukan runing load flow analysis untuk mengetahui rugi-rugi daya tanpa pengaruh THDi. Total rugi-rugi daya transformator tanpa terpengaruh THDi adalah sebesar 49,4 kW. Transformator DB 0608 memiliki rugi-rugi daya paling besar yaitu $3,2 \mathrm{~kW}$, hal ini dikarenakan transformator DB 0608 memiliki persentase pembeban paling besar diantara transformator lainnya.

\section{E. Efisiensi Transformator Tanpa Pengaruh THDi \\ Efisiensi transformator dapat dihitung} dengan persamaan 6 dengan hasil transformator DB 0608 memiliki efisiensi paling kecil yaitu 98,32\%, hal ini dikarenakan transformator DB 0608 memiliki rugi-rugi daya paling besar pada kondisi tanpa adanya pengaruh THDi.

F. Rugi-Rugi Transformator Setelah
Pengaruh THDi
Rugi-Rugi daya transformator setelah terpengaruh THDi dapat dihitung dengan persamaan 4 dan 5. Dalam tabel hanya ditampilkan 2 dari 67 transformator, yaitu transformator dengan kandungan THDi terbesar dan transformator dengan kandungan THDi terkecil.

Tabel 5 Rugi-Rugi Daya Transformator Setelah Pengaruh THDi

\begin{tabular}{|c|c|c|c|c|c|c|}
\hline No & Transformator & THDi & kVA & $\begin{array}{c}\text { Rugi- } \\
\text { rugi }_{\text {tanpa }} \\
\text { THDi (kW) }\end{array}$ & $\begin{array}{c}\text { Rugi- } \\
\text { rugi } \\
(k \text { akibat THDi } \\
(\mathrm{kW})\end{array}$ & $\begin{array}{l}\text { Rugi- } \\
\text { rugi } \\
(\mathbf{k W})\end{array}$ \\
\hline 1 & DB 449 & $6,8 \%$ & 250 & 0,5 & 2,2 & 2,7 \\
\hline 2 & KA 0992 & $24,8 \%$ & 100 & 0,3 & 12,02 & 12,32 \\
\hline
\end{tabular}

Pada tabel 5 dapat dilihat bahwa ransformator DB 449 dengan kapasitas 250 kVA memiliki kandungan THDi terkecil dan peningkatan rugi-rugi daya terkecil yaitu 2,2 $\mathrm{kW}$ atau $0,88 \%$ dari kapasitasnya. Sedangkan transformator KA 0992 dengan kapasitas 100 kVA memiliki kandungan THDi tertinggi dan peningkatan rugi-rugi daya terbesar yaitu 12,02 kW atau 12,02\% dari kapasitasnya.

Sebelum terpengaruh THDi rugi-rugi daya total untuk seluruh transformator pada Penyulang Kerobokan adalah sebesar 49,4 $\mathrm{kW}$, dan setelah terpengaruh THDi rugi-rugi daya mengalami peningkatan sebesar $542,31 \mathrm{~kW}$, sehingga total rugi-rugi daya untuk seluruh transformator pada Penyulang Kerobokan menjadi sebesar $591,71 \mathrm{~kW}$.

G. Efisiensi Transformator Setelah Pengaruh THDi

Dari hasil perhitungan rugi-rugi daya setelah pengaruh THDi, maka efisiensi transformator dapat dihitung dengan persamaan 6 .

Tabel 6 Efisiensi Transformator Setelah Pengaruh THDi

\begin{tabular}{|c|c|c|c|c|}
\hline No & Transformator & kVA & $\begin{array}{c}\text { Rugi-Rugi } \\
\text { Total (kW) }\end{array}$ & $\begin{array}{c}\text { Efisiensi } \\
\text { Transformator (\%) }\end{array}$ \\
\hline 1 & DB 449 & 250 & 2,7 & 98,76 \\
\hline 2 & KA 0992 & 100 & 12,32 & 87,02 \\
\hline
\end{tabular}

Pada tabel 6 dapat dilihat transformator DB 449 dengan kapasitas 250 kVA merupakan transformator yang memiliki nilai rugi-rugi daya terkecil dengan efisiensi tertinggi yaitu 98,76\%, sedangkan transformator KA 0992 dengan kapasitas 100 kVA merupakan transformator yang memiliki nilai rugi-rugi daya terbesar dengan efisiensi terendah yaitu 87,02\%.
H. Perbandingan Rugi-Rugi Daya dan Efisiensi Transformator Tanpa dan Setelah Pengaruh THDi

Pada tabel 7 dapat dilihat perbandingan rugi-rugi daya dan efisiensi transformator tanpa pengaruh THDi dan setelah pengaruh THDi.

Tabel 7 Perbandingan Rugi-Rugi Daya dan Efisiensi Transformator Tanpa dan Setelah Pengaruh THDi 


\begin{tabular}{|c|c|c|c|c|c|c|}
\hline No & Transformator & $\mathbf{k V A}$ & $\begin{array}{c}\text { Rugi- } \\
\text { rugi } \\
\text { tanpa } \\
\mathbf{( k W )}\end{array}$ & $\begin{array}{c}\text { Rugi- } \\
\text { rugi } \text { Total }_{\mathbf{k W})}\end{array}$ & $\begin{array}{c}\text { Efisiensi } \\
\text { Transformator } \\
\text { Sebelum } \\
\text { Pengaruh } \\
\text { THDi (\%) }\end{array}$ & $\begin{array}{c}\text { Efisiensi } \\
\text { Transformator } \\
\text { Setelah } \\
\text { Pengaruh } \\
\text { THDi (\%) }\end{array}$ \\
\hline 1 & DB 449 & 250 & 0,5 & 2,7 & 99,77 & 98,76 \\
\hline 2 & KA 0992 & 100 & 0,3 & 12,32 & 99,68 & 87,02 \\
\hline
\end{tabular}

Pada tabel 7 dapat dilihat transformator DB 449 dengan kapasitas 250 kVA mengalami peningkatan rugi-rugi daya terkecil yaitu $0,88 \%$ dari kapasitasnya dan penurunan efisiensi terkecil yaitu 1,01\%, sedangkan transformator KA 0992 dengan kapasitas 100 kVA mengalami peningkatan rugi-rugi daya terbesar yaitu 12,02\% dari kapasitasnya dan penurunan nilai efisiensi terbesar yaitu $12,66 \%$, hal ini disebabkan karena transformator KA 0992 memiliki kandungan THDi paling tinggi diantara transformator lainnya.

Rugi-rugi daya total pada seluruh transformator sebelum terpengaruh THDi adalah sebesar 49,4 kW dan setelah

terpengaruh THDi rugi-rugi daya
mengalami peningkatan sebesar 542,31 $\mathrm{kW}$, sehingga total rugi-rugi daya pada seluruh transformator di Penyulang Kerobokan adalah sebesar 591,71 kW.

$\begin{array}{lcr}\text { I. Penurunan } & \text { Kapasitas } & \text { Kerja } \\ \text { Transformator } & \text { pada } & \text { Penyulang } \\ \text { Kerobokan } & & \end{array}$

Penurunan kapasitas kerja transformator dapat dihitung dengan metode perhitungan THDF yaitu pada persamaan 8 kemudian dikalikan dengan kVA pengenal sesuai persamaan 9 .

Tabel 8 Penurunan Kapasitas Kerja Transformator di Penyulang Kerobokan

\begin{tabular}{|c|c|c|c|c|c|c|c|}
\hline No & Transformator & kVA & THDF & $\begin{array}{c}\text { kVA } \\
\text { Baru }\end{array}$ & $\begin{array}{c}\text { Derating } \\
\text { (kVA) }\end{array}$ & $\begin{array}{c}\text { Derating } \\
\text { (kW) }\end{array}$ & $\begin{array}{c}\text { Derating } \\
\text { (\%) }\end{array}$ \\
\hline 1 & DB 449 & 250 & 97,3 & 243,2 & 6,799 & 5,928 & 2,7 \\
\hline 2 & KA 0992 & 100 & 80,1 & 80,1 & 19,94 & 18,92 & 19,9 \\
\hline
\end{tabular}

Pada tabel 8 dapat dilihat bahwa pada transformator KA 0992 dengan kapasitas 100 kVA terjadi penurunan kapasitas kerja paling tinggi yaitu sebesar 19,9\%, sehingga kapasitas kVA baru pada transformator KA 0992 menjadi 80,1 kVA. Sedangkan pada transformator DB 0449 dengan kapasitas 250 kVA terjadi penurunan kapasitas kerja paling rendah yaitu sebesar $2,7 \%$, sehingga kapasitas kVA baru pada transformator DB 449 menjadi 243,2 kVA.

\section{KESIMPULAN}

Pada Penyulang Kerobokan hanya terdapat $3(4,5 \%)$ dari total 67 transformator yang memiliki kandungan THDi memenuhi standar IEEE 519-2014 dan 64 (95,5\%) dari total 67 transformator memiliki kandungan THDi yang tinggi dan melebihi standar IEEE 519-2014. Kandungan THDi terbesar terdapat pada transformator KA 0992 yaitu sebesar 24,8\% dan kandungan THDi terkecil terdapat pada transformator DB 449 yaitu sebesar 6,8\%. Sedangkan untuk THD tegangan seluruh transformator sudah memenuhi standar IEEE 519-2014.

Transformator KA 0992 dengan kapasitas 100 kVA mengalami peningkatan rugi-rugi daya terbesar yaitu $12,02 \mathrm{~kW}$ atau $12,02 \%$ dari kapasitasnya dan mengalami penurunan efisiensi terbesar yaitu 12,66\%, sedangkan transformator DB 449 dengan kapasitas 250 kVA mengalami peningkatan rugi-rugi daya terkecil yaitu $2,2 \mathrm{~kW}$ atau $0,88 \%$ dari kapasitasnya dan mengalami penurunan efisiensi terendah yaitu 1,01\%. Rugi-rugi daya total tanpa pengaruh THDi untuk seluruh transformator pada Penyulang Kerobokan adalah sebesar 49,4 $\mathrm{kW}$, dan setelah terpengaruh THDi, total rugi-rugi daya untuk seluruh transformator pada Penyulang Kerobokan menjadi sebesar 591,71 kW.

Transformator KA 0992 dengan kapasitas 100 kVA merupakan transformator dengan penurunan kapasitas kerja paling tinggi yaitu sebesar 19,9\%, sehingga kapasitas kVA baru menjadi 80,1 kVA. Sedangkan pada transformator DB 449 dengan kapasitas 250 kVA adalah transformator dengan penurunan kapasitas kerja paling rendah yaitu sebesar 2,7\%. Sehingga kapasitas kVA baru menjadi 243,2 kVA.

\section{DAFTAR PUSTAKA}


[1] IEEE Standards Association. 5192014. IEEE Recommended Practice and Requirements for Harmonic Control in Electric Power Systems. New York: IEEE Press; 2014.

[2] Wibowo dkk. Buku 4 Standar Konstruksi Gardu Distribusi Dan Gardu Hubung Tenaga Listrik. Jakarta Selatan: PT PLN (Persero). 2010.

[3] Rinas IW, Studi Analisis Losses dan Derating Akibat Pengaruh THD pada Gardu Transformator Daya di Fakultas Teknik Universitas Udayana, Teknologi Elektro. 2012; Vol. 11 (Januari-Juni): 23-29.

[4] Dugan RC, McGranaghan MF, Santoso S, Beaty KW. Electrical Power System Quality-Second Edition. The McGraw-Hill. 2004.

[5] Agusman C, Analisis Perhitungan Rugi-Rugi Daya Transformator Karena Harmonik. Depok: Universitas Indonesia. 2011.

[6] Gonen T. Electric Power Distribution System Engineering-Second Edition. United State of America: CRC Press. 2008.

[7] Tribuana N, Wanhar. Pengaruh Harmonik pada Transformator Distribusi. Diakses dari http://www.elektroindonesia.com/elekt ro/ener25.html, diakses tanggal 25 Mei 2018. 